\title{
Los 5 correctos en salud aplicados en la consulta
}

\author{
Doctor \\ Enrique Ardila \\ Editor \\ Revista Colombiana de Endocrinología, Diabetes y Metabolismo
}

Apreciado Dr. Ardila:

L a tasa metabólica basal (TMB) representa la integración de la actividad mínima de todos los tejidos en el cuerpo en condiciones de estado estable. El término basal se usó para distinguir entre la energía que se gasta al realizar actividad física y estar en reposo.

La TMB es la tasa diaria de metabolismo energético que un individuo necesita mantener para preservar la integridad de las funciones vitales. Generalmente, se expresa como la producción de calor o consumo de oxígeno por unidad de tamaño corporal.

Magnus-Levy acuñó el término metabolismo basal en 1899. Este término fue de gran valor para los primeros investigadores, debido a que enfatizó la necesidad de realizar los experimentos en condiciones estrictamente estandarizadas, como la ausencia de actividad muscular gruesa, estado posabsorbente, disturbio emocional mínimo, vigilia, condición nutritiva normal, ausencia de enfermedad o infección, y ambiente termoneutral.

Sin embargo, para la medición de la TMB se deben cumplir las siguientes condiciones:

- El sujeto debe estar completamente descansado, tanto antes como durante las mediciones. Debe estar acostado y completamente despierto.

- $\quad$ El sujeto debe estar en ayunas durante al menos 10 a 12 horas antes de tomar las medidas.

- El entorno en el que se toman las medidas debe ser termoneutral $\left(22-26^{\circ} \mathrm{C}\right)$ para que no haya un efecto termorregulador en la producción de calor.

- El sujeto debe estar libre de estrés emocional y familiarizado con el aparato utilizado.

En las personas con actividades normales, la cantidad de energía proporcionada por su alimentación debe cubrir las demandas del metabolismo basal más las cantidades adicionales necesarias para la actividad física asociada con los requerimientos corporales esenciales y también las impuestas por el trabajo físico asociados con la ocupación, actividades sociales y actividades de ocio.
La medición de la TMB en humanos atrajo un considerable interés durante la primera parte del siglo XX. Se utilizó principalmente para el diagnóstico de hipotiroidismo e hipertiroidismo. Las pruebas de TMB marcaron una nueva era en la medicina clínica. Bedale en 1923 describió el primer estudio exhaustivo para utilizar la TMB como base para estimar los requerimientos de energía humana (1), lo cual tomó mayor importancia en 1985 al publicarse el documento de la Food and Agriculture Organization/Organización Mundial de la Salud/Organización de las Naciones Unidas (FAO/OMS/ONU) (2) sobre los requisitos de energía y proteínas que propuso, por primera vez, el uso del gasto de energía (por lo tanto, de la TMB) en la ingesta de los alimentos para calcular las necesidades energéticas. Este nuevo enfoque para estimar los requerimientos de energía enfatizó la necesidad de estimar con precisión la TMB en poblaciones que viven bajo diversas condiciones climáticas y ambientales, pues la subestimación o sobreestimación de la TMB afecta gravemente la estimación general de los requerimientos de energía.

En este informe se deja claro, por primera vez, dos propósitos principales para determinar los requerimientos energéticos: el fin prescriptivo, es decir, para hacer recomendaciones sobre el nivel de consumo que se debe mantener en una población; y el segundo, el fin de diagnóstico; es decir, la evaluación de las necesidades alimentarias en una población (p. ej. macronutrientes).

Es importante reconocer que el objetivo principal de las primeras medidas de la TMB (1900-1950) fue diagnosticar el hipotiroidismo o el hipertiroidismo, no estimar los requerimientos de energía; por esta razón, se debe aclarar el tipo de población en las que se realizaron los estudios iniciales, el propósito y la función del cálculo para poder brindar de forma adecuada una aplicación óptima de la TMB.

En la última década se han usado mucho ciertos términos como metabolismo lento, metabolismo rápido, metabolismo acelerado y, por consiguiente, el concepto de medicamentos aceleradores o dietas para acelerar, entre otros; que más allá de un con- 
cepto mágico no aportan en el manejo del paciente con ciertas alteraciones, que es el público cautivo de este tipo de mercado.

Para las áreas asociadas con este problema es una obligación retomar los 5 correctos en salud. En el caso de la TMB, se debe considerar si es el paciente correcto (validación poblacional en pacientes obesos, con sobrepeso o normopeso), la fórmula correcta (uso de la fórmula que mejor se aproxime al paciente dada su condición nutricional y superficie corporal), la dosis correcta (¿se está calculando la TMB para el propósito adecuado?, cálculo de requerimientos energéticos), la vía correcta (instrumento adecuado con preparación adecuada) y el horario correcto (momento del día en el que se realice el cálculo de la TMB). El uso de la TMB para sugerir que no se sigue el plan nutricional o la actividad física correcta, o el uso de medicamentos aceleradores hace parte de una mala práctica, que se distancia de la máxima de la medicina primum non nocere, con la cual se debe siempre garantizar un acto honesto y asumir que la mala información, la confusión y la generación de metas poco alcanzables favorecen la frustración y mala adherencia del paciente con problemas de sobrepeso y obesidad, lo cual genera perjuicios directos en la resolución de su patología.

Ricardo J. Rosero Revelo Médico internista y endocrinólogo. Centro de Obesidad, Dismetabolismo y Deporte $\left(\mathrm{COD}^{2}\right)$, Clínica Las, Américas, Medellín, Colombia.

\section{Referencias}

1. Bedale EM. Energy expenditure and food requirements of children at school. Proceedings of the Royal Society of London. 1923;94:368-404.
2. Energy and protein requirements. Report of a joint FAO/WHO/UNU Expert Consultation. World Health Organ Tech Rep Ser. 1985;724:1-206. 
